\title{
Early Localized Lyme Disease
}

National Cancer Institute

\section{Source}

National Cancer Institute. Early Localized Lyme Disease. NCI Thesaurus. Code C119036.

An early stage of Lyme disease that may present within 3-30 days after a tick bite with a red, concentrically-expanding rash (erythema migrans), fatigue, chills, fever, headache, muscle and joint aches, and swollen lymph nodes. 